\title{
TAKING THE TOOL ANALOGY SERIOUSLY: FORMS AND NAMING IN THE CRATYLUS
}

\section{Imogen Smith $\star$}

University of the West of England (UWE)

It has been suggested that the so-called tool analogy passage of Plato's Cratylus presents us with a moderate linguistic naturalism that can stand or fall independently of the more unpalatable etymological and mimetic theories advanced later in the dialogue. This paper offers a reading of the tool analogy which argues that Socrates' employment of Forms (and in particular SpeciesForms), together with a careful distinction between the types of knowledge associated with making and using tools, aims to establish a radical linguistic naturalism that constrains the intrinsic properties of names. This should be clear if we take Socrates' claim seriously that names are tools: tools in general can only function successfully if they exhibit the relevant structural, compositional and (to some extent) material properties. Since Socrates claims that names are a class of tools and not merely like tools in some respects, as many have supposed, then what holds for tools in general must also hold for names.

\section{Introduction}

The Cratylus begins with a disagreement about names. ${ }^{I}$ Cratylus believes that names have to be naturally correct for their objects if they are to be those objects' names, while Hermogenes, on the other hand, believes that we may call objects anything we like: no one name is more correct for an object than another. Socrates is enrolled in the discussion to help them find out which one of them is right. Most of the ensuing discussion finds Socrates appearing to take the side of Cratylus by expounding a theory

\footnotetext{
* E-mail: imogen_e_smith@icloud.com
}

I would like to thank Prof. M. M. McCabe, Prof. Malcolm Schofield, Dr James Doyle and the anonymous referees at the Cambridge Classical Journal for their helpful comments and suggestions on earlier drafts of this paper.

I It has often been noted that the Greek word övou $\alpha$ has broader signification than the English 'name'; my use of the English 'name' in this essay should be understood broadly to encompass all referring terms, and, furthermore, 'referring term' should be understood to encompass both names of objects and predicate terms. (For further discussion of this point see, e.g., Ackrill (I997) 36; Fine (I977) 29I ff). 
that attempts to show why a name has to be naturally correct for the object that it names, and that offers an explanation of what such natural correctness amounts to.

Hermogenes' own view is deeply grounded in his belief that names are arbitrary. He claims, against Cratylus, that a name is simply 'a piece of voice' ( $\tau \hat{\eta} \varsigma \ldots$. $\varphi \omega v \hat{\jmath} \varsigma \mu$ óprov)

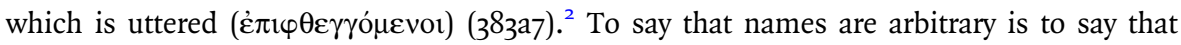
their intrinsic properties could have been otherwise without detriment to existing reference relations. Moreover, Hermogenes holds not merely that a name could have been different but that it can in fact be different: if one sets down a new name for something, that new name is 'no less correct' than the original, 'just as when we change the names of our slaves'. ${ }^{3}$ In contrast, Cratylus denies that names are arbitrary: he denies that 'Hermogenes' is Hermogenes' name, we may suppose, because 'Hermogenes' can be analysed to yield a particular description, 'offspring of Hermes', which is not true of Cratylus' interlocutor.

For the purposes of this paper I will characterise the salient negative feature of Hermogenes' position I wish to start from as follows:

- If linguistic naturalism were true then names would be non-arbitrary. Since names are arbitrary, linguistic naturalism is false.

If names are arbitrary, some mechanism is required by means of which members of a linguistic community can coordinate the use of these arbitrary sounds so as to enable successful communication. Convention, or intra-community agreements to use certain sounds in certain ways, seems to be the most promising candidate to fill the gap. ${ }^{4}$

However, many have considered Hermogenes' brand of conventionalism, which allows for conventions to be made by individuals alone, untenable. Accordingly, some have suggested that Hermogenes stands refuted within just a few pages, since his conventionalism about names is shown to entail a relativism about things that he is not prepared to commit to. ${ }^{5}$ Recent work, however, has demonstrated that Hermogenes'

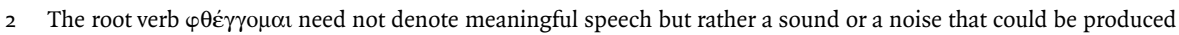
by an animal or even an inanimate object. (LSJ, s.v. I 2,3; cf. Ademollo (20II) 25)

3 Cra. 384 e.

4 Laurence (1996) 273 describes our pre-theoretic notions of conventionalism as follows: (I) Linguistic properties are not intrinsic properties of the utterances which have them. The marks and sounds we use could have (or could have had) linguistic properties other than those they in fact have; (2) Though we might speak any of a large number of possible languages, the members of a given linguistic community have a common interest in linguistic coordination (i.e., in speaking the same language), because they have a common interest in communication. The traditional source for modern views on conventionalism is, of course, Lewis's seminal discussion in Convention (1969); however, it would seem that Lewis would not have a problem with a Crusoe language whereby an individual could establish his own naming conventions (I82).

5 For examples of those who see Hermogenes presented as an extreme, or naive conventionalist, or swiftly refuted, see e.g., Baxter (1992) I8; Fine (1977) 295; Gold (1978) 242 ff.; Kahn (1973) 158-9; Ketchum (I979) I36; Reeve (1998) xiv. However, Hermogenes may get some sympathy from Davidson, (1984) 265 and (1992) II4, who has denied that the arbitrariness of linguistic expressions entails that their meanings are necessarily fixed by conventions. While accepting that linguistic coordination, in the sense of adhering to a common set of conventions, facilitates 
conventionalism is a more substantial thesis than had been previously thought, does not entail a general relativism, and that, instead of attempting to refute Hermogenes by proving as much, Socrates rather argues that linguistic naturalism follows from certain objectivist premises he agrees to. ${ }^{6}$

However, if Socrates wants to disabuse Hermogenes of the belief that linguistic naturalism is false, then he must either (a) demonstrate to Hermogenes the falsehood of his belief that names are arbitrary, or (b) advance a linguistic naturalism that holds even if names are arbitrary (and thus show that linguistic naturalism does not entail that names are non-arbitrary). Of course, (b) does not amount to a proof of linguistic naturalism, it merely defeats Hermogenes' particular objection to it. Nevertheless, in context, this should leave Hermogenes more amenable to an alternative, naturalist thesis.

Socrates' positive naturalist thesis comes in two parts. The discussion of $386 \mathrm{~d}-390 e$, known as the 'tool analogy', comprises a largely deductive argument making appeal to the Forms and proceeds from a rejection of a traditional Platonic concern, Protagorean relativism. ${ }^{7}$ Socrates then advances $(39 \mathrm{Ib}-427 \mathrm{~d}$ ) an etymological-mimetic theory of naming which appeals to the evidence of the phonetic and structural properties of actual Greek names in an attempt to show Hermogenes that names are non-arbitrary since their internal constitutions render them 'correct for' the objects they name.

Some commentators have supposed that the tool analogy and the etymological-mimetic theory of names are susceptible of independent evaluation: they need not stand or fall together. ${ }^{8}$ The tool analogy, on these interpretations, typically provides a general, functionalist account of names aimed at demonstrating the truth of linguistic naturalism (in some form or other) to Hermogenes; the etymological-mimetic account (which clearly pursues strategy (a)), provides one, but not the only possible, articulation of that theory's details. Thus if the details advanced by the etymological-mimetic theory are rejected, the general framework of the functionalist account may be left unscathed. ${ }^{9}$ Moreover, this

successful communication, he denies linguistic coordination is necessary for it. It may be the case that Hermogenes, like Davidson, denies that conventions - understood as interpersonal agreements - are necessary for successfully picking out and communicating states of affairs in the world to another, while accepting that interpersonal agreements nevertheless facilitate communication (he makes no attempt to diverge from common Greek linguistic practice in the dialogue (cf. Barney (I997) I54)).

6 Cf. Ademollo (20II) 8I; Sedley (2003) 54.

7 See, e.g., Ackrill (I997), Gold (I978), Ketchum (I979), Kahn (I973), White (I978), and (to some extent) Barney (200I) e.g. 47. I maintain that this argument is largely deductive, contrary to, e.g., Ketchum (I979) I38, who suggests the argument is analogical. The reasons for this will become apparent during the course of the discussion.

8 Ketchum (I979) I43 suggests that the tool analogy is primarily aimed at refuting conventionalism, while the remainder of the discussion of naturalism promotes a 'theory of meaning', which can stand or fall alone. See also, e.g., Ackrill (1997) 46-5I; Barney (200I) 47; Gold (I978) 245-6; Kahn (1973) I73; Silverman (I992) 44 and White (I978) 27In.I2.

9 Many suppose the etymological-mimetic thesis, which takes up about half the dialogue, is not intended in earnest. See, e.g., Arieti (r99I), Baxter (1992), Brock (1990), Gonzalez (1998), Keller (2000), Levin (2001), Nightingale (2003) or Sallis (I996). Others, consider the etymological tour de force is intended to show that Plato can best anyone in this literary genre (Barney (2000)). See Sedley (I998) for an opposing view. 
leaves open the possibility of reading the tool analogy as providing a different argument in favour of naturalism: one which pursues strategy (b), by advocating a moderate linguistic naturalism which constrains certain naming practices while at the same time allowing for arbitrary names.

One typical such reading envisages a moderate linguistic naturalism that requires merely that a name must (if it is to be a name) separate out a natural kind. On such a theory, as Fine suggests, "[i]f, for example, our language contains the word "trock", to be applied indifferently to trees and rocks, yet trees and rocks are distinct natural kinds, "trock" is an incorrect name; it does not divide up reality correctly'. ${ }^{\text {Io }}$ Irwin supposes that it is a conventionalism that allows this sort of error that Socrates seeks to reject. ${ }^{\text {II }}$ Thus so long as distinctions between names map genuine distinctions in nature, the intrinsic properties of an individual name could, we may suppose, be arbitrary. On this line of interpretation the conclusions of the tool analogy, which allow for arbitrary names, can survive the rejection of the etymological-mimetic thesis. ${ }^{\mathrm{I2}}$

This paper provides considerations against reading the tool analogy in this way: properly understood, the tool analogy argument is intended to show that names are non-arbitrary. Key to this interpretation are both Socrates' introduction of Species-Forms (389b8), which finely circumscribe the features of the specific tools that instantiate them, and his careful

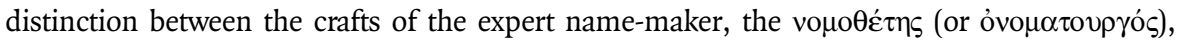
and the expert name-user, the dialectician. Traditionally, little has been made of this distinction by the defenders of moderate naturalism. ${ }^{13}$ Moreover, Ademollo, in his recent commentary on the Cratylus, has dismissed the distinction as unreal; yet, as I will suggest, taking the distinction seriously is required to give substance to his (to my mind,

Io Fine (I977) 296. See also Kretzmann (I971) I3I-2.

II The evidence for this view is sought by Irwin (I999) and Kretzmann (I97I) at 394d, where Socrates claims that it is fitting to give the offspring of a lion the name of a lion. There is no doubt that the interpretation of the tool analogy presented here would support this claim, but it is not the only consequence of it; rather this follows a fortiori from the stronger conclusions I suggest.

I2 Prima facie, it is unclear on this view, however, which of Hermogenes' original claims are being attacked. Hermogenes suggests there is no reason why a particular object (or kind) should be called one name rather than another; nowhere does he claim that it is legitimate for one natural kind to share a name with a different natural kind. Hermogenes' agreement, at $385 \mathrm{a}$, that one may call one and the same thing 'horse' in private and 'man' in public should not be taken to imply that two distinct kinds can share a name in the relevant sense: he never claims that the same name could be used of both man and horse in the same context of use, be that public or private. Furthermore, the mention of Greek and barbarian languages at $390 \mathrm{o}$ can but call to mind Plt. 262d ff., where the Stranger notes that dividing human beings into classes with the names 'Greeks' and 'barbarians' is a mistake since it fails to cleave nature at the joints. Pace Irwin (I999) I48, 'barbarian', in the Statesman at least, nevertheless appears to succeed in picking out its mongrel class when so used.

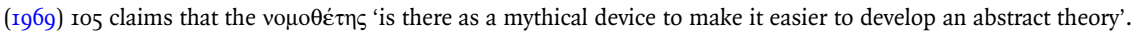

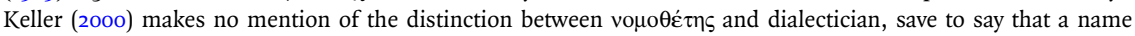
(unlike other tools) lacks the specificity to require an expertise of making - it is rather like a paperweight (292-3), yet it follows from the claim that name-making is an expertise that names, on this account, have just that specificity. 
correct) suspicion that the notion of Species-Forms 'may be, as a matter of fact, much more tightly connected with the purpose of naturalism than is usually supposed'. ${ }^{4}$

The specialised ability afforded to the name-maker in looking to the Species-Form of each name and setting it in sounds and syllables is at the core of the conclusion of the tool analogy (39od7-e5), where Socrates does not claim to have shown (merely) that Hermogenes' conventionalism is wrong, but that 'Cratylus speaks the truth ( $\dot{\alpha} \lambda \eta \theta \hat{\eta} \lambda \dot{\varepsilon} \gamma \varepsilon 1)$ when he says that names exist by nature for things' (39odII-eI). It will be to the detriment of any interpretation, then, not to give the craft of name-making its due.

In section I, I suggest that Socrates' discussion of successful actions at the opening of the tool analogy constitutes no objection, by itself, to Hermogenes' original claim that we can call objects by any name that we like. The agreement elicited that naming, as all actions, is subject to objective success criteria does not entail that those criteria themselves could not be determined by conventions or something similar. This early passage at most demonstrates that a name's use must be in accordance with what it was established for.

In section 2, I suggest that Socrates' subsequent introduction of a 'Species-Form', which a name must possess in order to be a name for a particular object, sets natural constraints on naming-conventions themselves. The Species-Form accounts for a particular name's necessarily having the particular function that it does (say, the function of naming a cat rather than a dog) and strictly constrains how it may subsequently be used. However, I suggest, we must take more than mere functions into account if we are to make sense of the claim that the name-maker's unique skills afford his names authority alone.

Thus, in section 3, I go on to suggest that the Species-Form, understood in the context of the toolmaker's craft, must not only constrain a name's function, but must also constrain its structural features: what it must be like in order to function as a name for its nominatum. If a tool's user knows how to use a tool (and so primarily has knowledge of its function) and the maker's knowledge is distinct from this, then there are grounds to suppose that the maker's knowledge includes, inter alia, knowledge of facts about what a tool must be like in order to perform its function. Moreover, the requirement for collaboration between maker and user in tool production cannot be easily made sense of unless Socrates intends us to view Species-Forms as determining the structural properties of names. I then suggest that by examining certain claims in the opening passages of the etymological discussion (391c10-395a2), we may best understand the name-maker's task of embodying the Form in the matter as his encoding informational content in sounds and syllables, in virtue of which a name so created can perform its intended task. Apparent minor differences in the informational content of names that Socrates claims to be 'the same' can thus be explained in terms of the approximation of particulars to the Forms that they instantiate.

In the concluding section, I make some tentative suggestions as to the implications of this reading of the tool analogy for our understanding of the Cratylus as a whole.

I4 Ademollo (20II) I38-44. 


\section{The 'tool analogy'}

I attach the traditional label of 'tool analogy' to the first part of Socrates' naturalist thesis, but here I introduce a caveat: the tool analogy passage is not an argument by analogy. It is important to recognise that Socrates does not claim that names work analogously to tools; he claims that they are tools. Consequently, we cannot interpret the relevant passages as if Plato thought of names as sui generis entities that merely happen to share certain properties with tools, so that a discussion of tools may shed light on some aspects of names - as if, when it serves to make Plato look more hospitable to modern semantic doctrines, we may ignore the constraints imposed by the general claims made about tools in the passage. ${ }^{15}$ We risk misinterpreting Plato here unless we acknowledge that the socalled tool analogy classifies names as tools, and not merely as like tools in some respects.

In the first stage of the tool analogy (386d8-389a4) Socrates makes some remarks about tools, and names as a class of tools, which together imply certain facts about naming. These can be set out as follows:

I. All objects exist independently of us; they have their own independent, stable natures. (386d8-e4)

2. Actions, as a class of objects, also have their own independent natures. (386e6-8)

3. In order for an action to be successful, it must be performed according to its own nature, the nature of the object that the action is performed upon, and with the tool that is naturally fitted for the purpose, not merely according to the wishes of the agent. (387ai-b4)

4. Speaking is a class of action, and is subject to the success conditions of 3 . (387bir-c4)

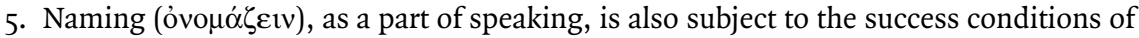
3. $(387 \mathrm{c} 6-\mathrm{d} 8)$

6. Each type of action requiring a tool for its performance requires a specific type of tool (weaving requires shuttles, boring requires trepans etc.). (387dio-e 3 )

7. The tool required for naming is a name. $(388 a 6-7)$

8. Naming is defined as dividing things as they are and teaching something to one another. (388bio-II)

9. Therefore, the function of a name is to divide up reality and teach something to another. $(388 \text { bro-cI })^{16}$

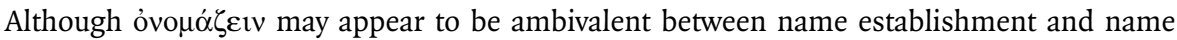
use, the parallel with weaving and boring (which use tools), suggest that name use is intended here. ${ }^{17}$ There are, we are told, objective conditions which govern what counts as

I5 See, e.g., Evans (20II) 34I-2.

I6 I take the 'function' of $a$ to be defined by the response to the question 'what do we do when we $\varphi$ with a?'

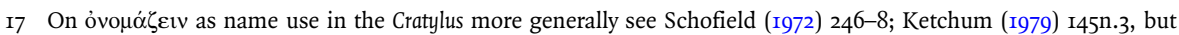
cf. Barney (200I) 6n.8. 
a case of successful name use: whether I use the vocabulary available to me successfully is not simply a matter of my own whim, I must use it in such a way as to separate things as they are and teach something to another. ${ }^{\mathrm{I}}{ }^{2}$ Likewise, my successfully driving a screw is not merely a matter of my merely deciding that I have done so: if, Socrates proposes at $387 \mathrm{c}$, we use the tool that is not naturally suited for our intended task we will 'go wrong and accomplish nothing'. ${ }^{\text {I9 }}$

Although Socrates has elicited agreement that there are necessary connections between tool, action and object to be acted upon, no reason has yet been given as to why, in the case of names, these necessary connections cannot be constituted by something like convention or agreement. ${ }^{20}$ A typical conception of names and naming today would accommodate the idea that the fact that names are conventional is not in itself dependent on us, rather it is only the individual naming conventions themselves that are dependent on us. The fact that conventions determine name use could itself constitute part of a name's nature. Nothing that Socrates has said so far, therefore, rules out the possibility that successful use of a name may still be use in accordance with linguistic conventions, particularly those conventions made at establishment (dubbing) events. ${ }^{2 I}$

At 388d6-e3, we are told that names available for our use derive from vó

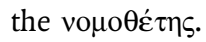

Soc: Whose work does the teacher use when he uses a name?

Her: I don't know.

Soc: Don't you know this either: who provides us with the names we use?

Her: Indeed I don't.

Soc: Don't you think that vó $\mu$ os is the provider of these things?

Her: That's likely.

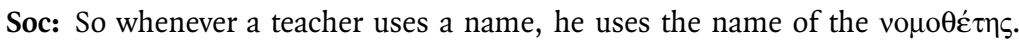

388d6-e2

The claim that a name-maker is the originator of names implies the rejection of the

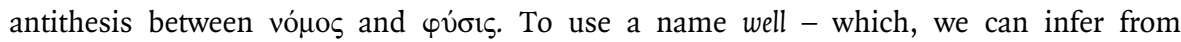

I8 A name's 'teaching something to another' could, as yet, range from merely communicating something to another when used (and so provide another with new information) to the name itself teaching something to another by yielding arcane information when subjected to analysis (cf. Ademollo (20II) IOI-2). 'Dividing reality as it is', in the etymological section of the discussion, becomes a matter of separating out a natural portion of reality by encoding a description of that portion of reality in a name, thus marking off what its object is from what it is not. Finally, in the mimetic stage of the theory, separating out a natural portion of reality by encoding a description in a name is redefined as combining elemental sounds (letters) that imitate the essential components of that portion of reality. The investigator can therefore learn something from the name in the stronger sense of 'teaching something to another'; however, to understand the definition in the strong sense at this point would surely be to beg the question against Hermogenes.

I9 Cf. Keller (2000) 29I-2.

20 See Anagnostopoulos (1972) 710 ff. and Ketchum (1979) 136 for further discussion of this point.

2I As Barney (I997) notes, Hermogenes does indeed make a distinction between name use and name establishment in his own conventionalist thesis. 
$387 \mathrm{~d} 4$, means to use it in the naturally correct way - is to use a vómos in line with the

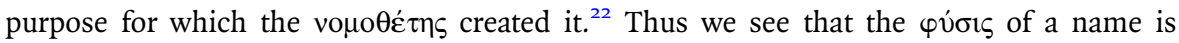
not independent of vómos, but is at least in part constituted by it.

The claims so far imply no more than that a tool is used successfully if it used in accordance with what it was made for. Since we have not yet been told how a name should be made, Hermogenes can thus far accept that names should be used in line with vónor that have been set down; the question of whether the names set down by the name-maker are themselves arbitrary is yet to be addressed.

\section{Constraints on name-making and the Species-Form}

When the discussion moves from using names to making names it becomes apparent that the successful establishment of vó $\mu o 1$ is itself subject to external, natural constraints. Socratic 'naming conventions' - at least as far as this dialogue is concerned - are not 'up to us', but rather, like tools, they must be manufactured in the correct way to succeed as naming conventions at all. The expert name-maker knows how to create a name just as the expert shuttle-maker knows how to create a shuttle. The question is, then, in what does this knowledge consist? Once this is established, the natural constraints on namemaking will become clearer.

Socrates first convinces Hermogenes that a tool must be made by the relevant craftsman. This craftsman is the only person who can make that tool because only he has the requisite expertise $(\tau \dot{\varepsilon} \chi \vee \eta)$. The making of shuttles is the province of the carpenter; analogously the

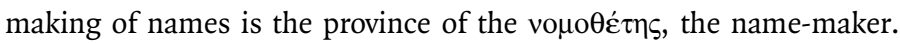

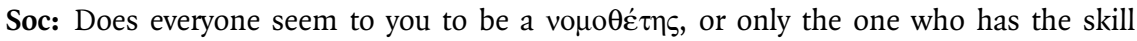
$(\tau \varepsilon \dot{\chi} \chi \eta)$ ?

Her: Only the one who has the skill.

Soc: So the setting of names is not the province of everyone, Hermogenes, but of a

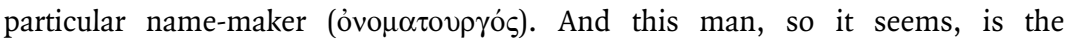

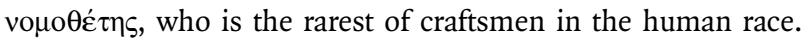

Her: So it seems.

$388 \mathrm{e} 4-389 a 4$

Socrates next claims that each class of tool (names, trepans, shuttles etc.) has a Form,

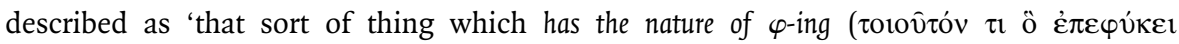

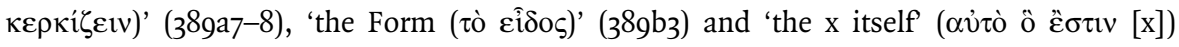
(38gb5). This Form is most likely envisaged as a paradeigma or 'pattern' which the craftsmen looks to as he fashions his tool (389a5).

22 See Ademollo (20II) I0 5 for a discussion of $\kappa \alpha \lambda \hat{\omega} \varsigma$ at $388 \mathrm{c} 5-7$ and $39 \mathrm{Ib}$ as equivalent to óp $\theta \hat{\omega} \zeta$. Later (43Ic-433c), a clear distinction between 'finely' and 'correctly' is made with the possibility that names may vary in quality and yet still be names. 
Finally, Socrates posits a further kind of specific $\varphi v i \varsigma s$ that renders specific tools within a class appropriate for a specific product. The shuttle must have the Form of a shuttle, but, in addition, it must have the specific nature required to weave a particular type of cloth (cotton, for example).

Soc: Now, when it is necessary to make a shuttle for light garments or thick or woollen or linen ones, or some other kind of clothing, all the shuttles must have the Form, but whatever nature is best for each type of woven product, it is necessary to put this nature into each tool.

38gb8-cI

A tool's specific nature is described in the text as:

I. 'The nature of a tool such as is naturally finest for each product': oí $\alpha$ ' $\dot{\kappa} \kappa \alpha \sigma \omega$

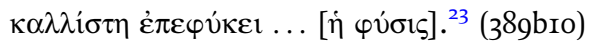

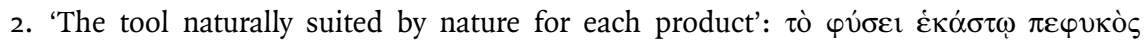
öprovov. (389c4)

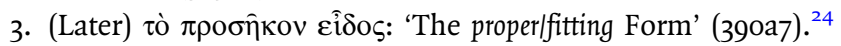

I will refer to this as the Species-Form, because it explains the difference between species of a genus of tool, rather than between genera of tools.

The Species-Form is unique to the Cratylus in the middle-period dialogues and there has been some debate as to whether to count these Species-Forms among the Forms proper. ${ }^{25}$ However, the similarity in language between the description of the Species-Forms and more traditional generic Forms and, moreover, the similarity between their qualities and those favoured by Plato in his accounts of traditional Forms (they have independent existence and are objects of knowledge (389c6-8)) suggest that they are conceived of as types of Forms. ${ }^{26}$ Merely for a name to be modelled on the generic form will not do. Just as a shuttle must have the Species-Form appropriate to weaving wool in order to be used to

23 I take $\dot{\varepsilon} \alpha \dot{\alpha} \sigma \tau \omega$ to be anaphoric of the earlier $\lambda \varepsilon \pi \tau \hat{\omega} \dot{\mu} \mu \alpha \tau \dot{\omega} \omega \kappa \tau \lambda$., and translate $\dot{\varepsilon} \kappa \alpha \dot{\sigma} \sigma \omega$ as 'each product' rather than 'each task' (as Reeve (I998) does). Contra Ketchum (I979) I46n.9, there is no reason to think that $\dot{\varepsilon} \kappa \alpha \sigma \tau \omega$ is not

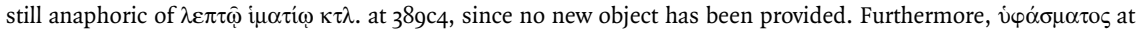

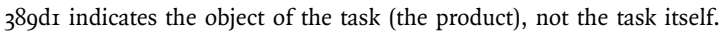
These distinctions follow Calvert (I968) 29-30. Cf., e.g., Ademollo (20II) II7-I8; Gold (I978) 233-8; but Anagnostopoulos (I972) 7Io for an opposing view. We might see some connection with the mention of genus and species in the later dialogues, e.g., Sph. 258 and Phlb. I2-I7. However, the mention of species in these places is not clearly connected to an exposition of the Forms as understood in the middle period dialogues.

26 According to Calvert (I970) 26-34, Species-Forms are immanent, as opposed to generic Forms which are presented as wholly separate: such a distinction seems to be made and maintained quite rigorously through this passage. Yet while the objects are said to 'have' these Forms at $389 \mathrm{~b}$, 'have' expresses a vague relation: it does not follow from this that the Species-Forms are immanent or abstract. See Calvert, ibid., for a similar view of the vagueness of हैं $\varepsilon 1 v$. 
weave woollen products, a name for a dog, it seems, must likewise have the Species-Form appropriate for naming dogs. ${ }^{27}$

Thus the introduction of Species-Forms for individual names appears to collapse the distinction between a name's being a correct name for an object and its being a name for that object at all. ${ }^{28}$ A putative name for $\mathrm{x}$ will not be a name for $x$ if it does not 'have' that correct Species-Form. ${ }^{29}$ It is likely, then, that one cannot press a name created to name one thing into service of naming something else for which it was not created. ${ }^{30}$

We are further informed that the setting of the Species-Form into the matter is the province of the special expertise of name-making. The expert name-maker must know how to set this Species-Form in his sound-matter, and only names constructed on this basis have legitimacy. ${ }^{31}$

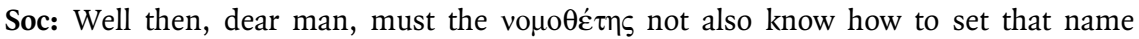
suited by nature to each object in sounds and syllables, and mustn't he make and set all the names while looking to that-thing-which-the-name-itself-is, if he intends to be an authoritative (кúpıø) setter of names?

$389 \mathrm{~d} 4-\mathrm{d} 8$

Many have supposed that in claiming a name-maker must embody a Species-Form Socrates merely supposes that he must embody a certain specific function: the name of a dog, say, must simply have or embody the function of naming a dog. ${ }^{32}$ This explanation is unsatisfying. The

27 Silverman (1992) 36 is thus mistaken in implying that a bad carpenter could make a generic shuttle.

28 Ademollo terms this the 'redundancy theory' of correctness (20II) passim, but esp. 24, 98. While Socrates suggests at $387 \mathrm{a} 8-9$ (cf. 387c3-4) that if we use the incorrect tool we will 'go wrong and accomplish nothing', this does not rule out the possibility that there may be different degrees of correctness (cf. 392a-d); Socrates may therefore allow that names embody a Species-Form to a greater or lesser degree of approximation, but, nevertheless, we might suppose there is a limit beyond which a name will not be able to function as a name for its nominatum. Cf. Sedley (2003) I42-6.

29 Williams ( 1982 ) 83, points out that Cratylus' theory collapses the distinction between a name's being correct and a name's being a name. However, he does not note that this is an implication of the claim that names have Forms. It is not then clear that Williams is correct in suggesting that Socrates' later distinction between correctness and reference is not made at the price of his own theory.

30 If Socrates were following the model of functions derived from the example of knives in R. $352 \mathrm{~d}-353 \mathrm{~b}$, he could mark a distinction between correctness and success conditions for making a name: what something would best be called versus what something could be called at a pinch (cf. Millikan (I984) I-II). It is not immediately obvious how this characterisation of function (which is silent on the Forms) could be rendered consistent with the claim that artefacts have Forms: that would seem to entail that a screwdriver cannot become a wrench - even temporarily - any more than a sunflower can start growing apples. For a screwdriver to perform the function of a wrench, for example, it would somehow have to participate in the relevant Form - and on the model given in the Cratylus it is not immediately clear how this could happen. However, an anonymous referee for the Cambridge Classical Journal notes that given an inherent imperfection in a particular's instantiating a Form, this may allow it to sufficiently instantiate one Species-Form while simultaneously instantiating another 'nearby' Form. Thus a butter-knife might also cut fish passably well, say. It does not follow that it could thus instantiate the Form of a pruningknife. For further discussion on names as imperfect instantiations of Forms, see \$3.

3I I follow Ademollo (20II, I35-6) in considering the name-maker to be authoritative (кúpıos) in the sense of 'legitimate' (or perhaps 'genuine').

32 See, e.g., Ackrill (1997), Kahn (ig86), Ketchum (1979), Sedley (2003). 
Forms have been introduced to explain to Hermogenes why names are naturally correct; however, identifying Species-Forms with functions leaves us with the bland suggestion that, once the craftsman has embodied this ideal function in matter, the tool will be capable of performing whatever real function the craftsman has constructed it to perform. An informative answer to the question 'Why does this name name this object?' must be more than 'because this name has the function of naming this object'. ${ }^{33}$ Species-Forms have to be more than functions if they are to explain those functions. ${ }^{34}$ More pertinently, it is unclear what knowledge of a Species-Form an expert name-maker can have if it is characterised purely in terms of function: a wool-shuttle maker cannot make a wool-shuttle purely in virtue of his knowledge of what a wool-shuttle does. It would be wise, then, to consider further what knowledge is involved in the making of tools in general, and names in particular.

\section{Name-making and name-using}

We have seen Socrates establish that making tools belongs to the province of expertise or $\tau \varepsilon \dot{\chi} \chi \alpha \alpha$. To be an expert - to have a $\tau \dot{\varepsilon} \chi v \eta$ - is to possess a particular body of knowledge; the expert is in a position to know, and give an account of, the objects of his expertise, thus communicating his knowledge to others, making more craftsmen like himself. ${ }^{35}$ The claim that name-making is a $\tau \dot{\varepsilon} \chi v \eta$ implies that there is a special kind of knowledge involved in the construction of names distinct from the knowledge involved in using them. Given that names are classed as tools, considerations derived from toolmaking in general might elucidate what such knowledge might be.

A carpenter knows how to make a shuttle. Socrates and Hermogenes have just agreed that a shuttle is for dividing weft and warp at the loom. The carpenter, however, must know a lot more than this in order to make a shuttle. Importantly, he must know what a shuttle must be like in order to divide weft and warp. ${ }^{36}$ In other words, he must know what properties a shuttle must have in order to weave a particular kind of fabric. He must know something about what a shuttle does, of course, but his discovery of the Form of the shuttle (389c4) does not involve learning how to weave. That is the province of the weaver.

33 Ketchum (I979) I43 acknowledges this consequence, but seems happy to accept it nonetheless.

34 Cf. Bestor (I980) 3I4-I5, for a similar point. One might attempt to make the answer more informative by specifying in further detail what the claim that a name's Form is a function amounts to. Some who attempt to do so equate a name's function with its meaning. Ackrill (1997) 43-4, for example, states that the name is identified solely by reference to the job it does and subsequently claims the Form of a name is its meaning (where 'meaning' is understood as some concept or other). He infers from this that structural considerations are of no account: the intrinsic properties of a given name have no role to play in determining what it picks out. On his interpretation, however, he has to concede that the tool analogy does nothing to refute Hermogenes. Nor can he provide a connection between the tool analogy and the rest of the dialogue, which he admits is largely devoted to identifying appropriate sounds. Prt. 32ra ff.; Men. 87b ff.

36 This is surely suggested by the description of the Form of shuttle as of thing that naturally weaves', at 389 a. 
Thus it should be clear that we cannot straightforwardly identify the Form of F with F's function: the Form of a shuttle, for example, is not weaving, just as the Species-Form of a wool-shuttle is not wool-weaving. If Socrates' account of toolmaking is intended to identify success conditions for tool production, the equation of Form, or Species-Form, with function alone cannot make sense of it. Rather, when Plato speaks of the Form of a tool that the craftsman looks to, it is likely that he means us to understand it as the object of the craftsman's knowledge about shuttles, which includes, inter alia, the characteristics that a tool must have in order to perform its function: its shape, composition, and, perhaps even to some extent, material properties. ${ }^{37}$ I will term such properties structural properties. It has already been agreed that names are tools; a fortiori the Forms of names can also be so characterised.

As the passage proceeds, we see that the refining of a tool is not a one-man operation, according to Socrates: the toolmaker lacks some of the required knowledge, which only the professional user has. In the case of names, the expert user is the dialectician. ${ }^{38}$

Soc: Now who then will know whether the proper Form of the shuttle has been set in the wood - whatever kind of wood it is? The one who made it, the carpenter, or the one who will use it, the weaver?

Her: It's reasonable to say that it's rather the one who is going to use it, Socrates.

Soc: Who is it that will use the work of the lyre-maker? Is not this man the one who knows best how to oversee the making of the lyre and who would know whether it has been well made or not?

Her: Certainly.

Soc: And who's that?

Her: The lyre player.

Soc: And who will be best placed to know about the products of the shipbuilder?

Her: The captain.

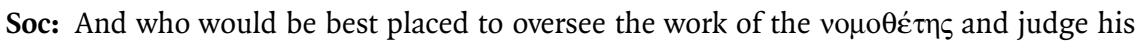
work - both here and abroad? Is it not the one who will use it?

Her: Yes.

Soc: And this is the man who knows how to ask questions?

Her: Of course.

Soc: And also how to answer them?

Cf. Patterson (1985) I3I-2:

[T] he fact that the intelligible realm determined by the Forms includes a functionally defined Form of Pruning Knife entails that to be a worldly pruning knife is to be something suited to serve a specific function having a place in the natural order. A sensible object can be this only if (a) there is a natural type of work or function to be performed, and (b) the object's (corporeal) parts are so constituted and distributed that it is suited to perform that work. When these two conditions are met, the piece of metal participates in the separate, intelligible Form of Pruning Knife 'fixed in the nature of things'.

38 Given that we have already been told that the user of names is a teacher at $388 \mathrm{c} 6$, it would seem safe to identify him with the dialectician here. 
Her: Yes.

Soc: And would you call the man who knows about asking and answering questions anything other than a dialectician?

Her: No, this is what I'd call him.

Soc: So then: the job of the carpenter is to make the rudder under the supervision of the captain, if he intends the rudder to be a fine one.

Her: It appears so.

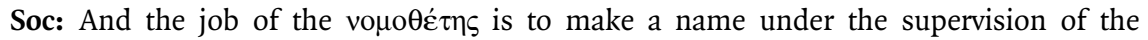
dialectician, if he intends to set down a name well.

39obI-39od7

The expert user, then, oversees the maker during the production of a tool and judges the finished product. The wording here is very careful: Socrates does not say that the user knows the Species-Form but that he knows whether that Form has been set in the matter. The maker was earlier described as having discovered the Species-Form, and knowing how to set that Form in matter. The knowledge of each is characterised differently. ${ }^{39}$ Although the user is depicted as overseeing the maker, clearly they both know something, since they are both characterised as practitioners of crafts. ${ }^{40}$ And since they both know something, they must stand in some relation to a corresponding Species-Form. ${ }^{4 \mathrm{I}}$

Since the toolmaker's knowledge primarily concerns the structural properties of a tool, I will speak of him as knowing the Species-Form in its structural aspect. Since the user's expertise primarily concerns a tool's use, it would be most natural to suppose he knows the Species-Form in its functional aspect. However, in the tool analogy, the expert user's role is not exhausted by merely using the maker's products. Socrates tells us that he must collaborate with the toolmaker in producing the tool, and judge whether the tool is well made once it has been produced: he must be qualified to know whether the form has been

39 This parallels Euthd. 289a-d, where the makers and users of artefacts are said to have distinct knowledge related to the same object: 'the art which makes is one thing and that which uses is another; they are quite distinct although they deal with the same thing'.

40 There are similarities with R. 6oIc-6o2a, although there the maker is ascribed only true belief. However, the purpose of that passage is primarily to demonstrate the inferiority of the imitator (who does not even have belief): thus, as Ademollo (20II, I42n.II6) suggests, it is unwise to attempt to import the claims made there into this passage.

$4 \mathrm{I}$ Cf. Aristotle Ph. 2, I94az6 ff.:

There are two skills that govern matter and have knowledge: the skill of using and the skill that directs the making. So the using skill is also, in a way, directive, but it differs from the other in that it has knowledge of the form, whereas the skill that directs the making has knowledge of the matter. So the helmsman knows the form of the rudder and directs, and the other, the maker, knows from what kind of matter and by what changes the rudder will come to be.

Accepting that Aristotle is using different categories from Plato (and so the comparison will not be complete in this way) we can nevertheless see him acknowledging that two forms of knowledge are associated with artefacts corresponding to production and use. Charlton (I970, n. ad loc.) suggests that Aristotle is referencing the Cratylus here. 
set in the matter. Thus even the expert user's knowledge cannot be reduced to knowledge of function alone. A weaver telling a shuttle-maker that such-and-such a shuttle fails to discharge a particular function does nothing to help the maker improve on his efforts. In order to supervise the construction of a tool, the user must, then, also have knowledge of a tool's structure, at least in so far as it conduces to a particular function, to explain to the maker what alterations must be made to improve a tool's performance. ${ }^{42}$

It would be difficult to see why Socrates makes a distinction between maker and user if knowledge of the Species-Forms of names amounts only to knowledge of their functions. Nothing here would qualify the maker over the expert user in the making of tools. Nor would the user's judgement aid in the collaborative process if he could not direct the maker to improve the structure of his tools. Since a name is a tool, the expert user's knowledge of a Species-Form of a name must also involve knowledge of the structural features that they lend to their particulars.

In considering further what kind of structural features might support a name's function let us return to $388 \mathrm{~b}-\mathrm{c}$, where we are told that when we use names we 'teach something to one another and divide things as they are' and, thus, that a name is a tool for instructing and dividing ousiai. We might plausibly infer from this, as Sedley does, that if the function of names in general is to separate ousiai, the function of a particular name must be to separate out the particular ousia of an object that a user intends to pick out, where ousia need not be understood in any strict sense as essence (although this might be the ideal), but in a 'weaker and more inclusive sense'. ${ }^{43}$ Thus a name will separate out its nominatum/nominata from the rest of reality by identifying some unique feature of it.

The competence of the dialectician to judge whether names are well made also depends largely on his knowledge of the nominata (or their ousiai) that they will be used for. Yet if this knowledge is to have any substantive role in his judgement of whether a particular name can perform its intended function, then it would seem that there must be some corresponding feature of that name which can be judged in the light of the nature of the nominatum.

Socrates suggests precisely such a feature in the pages following the tool analogy, where he claims that a name, decoded in the correct way, should yield informational content that captures the ousia of its nominatum. The etymological discussion shows this informational content to be a form of identifying description, which the name-maker compresses and encodes into a name. So, for example, the identifying description for 'wisdom' (4IId4-5),

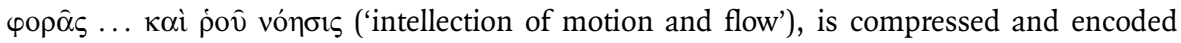

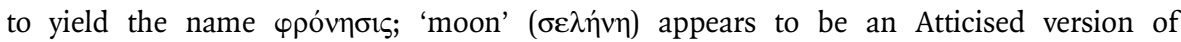
$\sigma \varepsilon \lambda \alpha v \alpha i \alpha$, in turn compressed from $\sigma \varepsilon \lambda \alpha \varepsilon v v \varepsilon o \alpha \varepsilon 1 \alpha$, which is itself an encoding of the

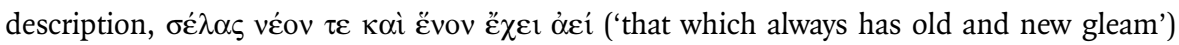
$(409 b-c) .{ }^{44}$ The skill of the name-maker does not stop here, it would seem; if a name can

42 Pace Silverman (I992) 38.

43 Sedley (2003) 84.

44 I thank an anonymous referee for the Cambridge Classical Journal for pointing me in the direction of this perspicuous example. 
be analysed into a description, and the names in that description can be analysed into further descriptions, we risk an infinite regress. Socrates therefore proposes the existence of certain primary or atomic names into which these compound names are ultimately resolved (42Id$422 b)$. These primary names imitate their objects at the atomic level. In effect, when somebody makes a name they work in much the same way as someone who tries to represent reality through painting, blending together pigments to imitate his object (424d ff.). Thus we are told, for example, that rho indicates motion, tau, rest and binding, and omicron, roundness. The knowledge of the name-maker, then, also includes knowledge of the classification the imitative properties of these primary name-sounds, and the primary classes of being they track (424c6-425a2). ${ }^{45}$ The dialectician, in his particular capacity of overseeing the name-maker and judging his products, on the other hand, need not know how to encode names, rather he must know how to decode them. ${ }^{46}$ Once he has done this, he may see whether the informational content contained in a name identifies his desired ousia: whether the Species-Form has been embodied in the matter.

There is good reason, then, not to dismiss, along with Ademollo, Socrates' carefully made distinction between name-maker and dialectician as unreal. While voicing his suspicion that 'the notion of the specific forms of name may be, as a matter of fact, much more tightly connected with the purpose of naturalism than is usually supposed', Ademollo nevertheless considers the distinction between name-maker and name-user to be of merely dramatic significance: it sets up Socrates as the dialectician who is competent to judge the efforts of the name-maker (and thus decide whether his names have been well made or not (cf. 39ob6)) in the etymological investigation that is about to come. ${ }^{47}$

Ademollo believes that Socrates does not seriously intend the distinction between namemaker and dialectician because the name-maker must have 'some sort' of knowledge of the nature of the thing named in order to appropriately embody a name for that thing in the sound-matter, - 'which we should expect to be the dialectician's hallmark'. ${ }^{8}$ This, however, seems to be a weak ground for discounting the distinction in the particular case of names. It ignores my warning to take the claim that names are tools seriously; any

45 Cf. 426a-b: 'It's clear that anyone claiming to be expert ( $\tau \varepsilon \chi v i \kappa o ́ v)$ in these matters must especially be able to give clear explanations of the primary names, or he can be sure that he will be talking nonsense about the compound ones.'

46 Sedley (2003) 4I impresses upon us the distinction between the skill of encoding and the skill of decoding: 'our job as etymologists is not to repeat the work of the name-makers, but to reverse it, decomposing what they composed and thereby decoding what they encoded'. I assign this decoding skill to the dialectician, in his supervisory role.

47 Ademollo (20II) 138, I44.

48 Ademollo (20II) I43 also considers the fact that the dialectician is not mentioned again after 39Id speaks against a serious distinction between the two crafts. This is odd, since he holds - plausibly - that the role of the dialectician is precisely the one adopted by Socrates for the remainder of the dialogue. One might, at any rate, suspect it, contrary to Socrates' characteristic modesty to impress upon us that he is an expert in using names, yet I suspect that the dialectician is indeed mentioned again as 'one who knows about names' at 394b3-4 (see \$3). Moreover, at $425 \mathrm{a}-\mathrm{b}$, it seems that Socrates, in his role as dialectician (judging whether primary and compound names have been set down correctly), clearly distinguishes his activities from those of the original name-makers. 
toolmaker would struggle to make his tool if he had no knowledge of the use to which it would be put: the same is a fortiori true of names. ${ }^{49}$ Moreover, Socrates has made explicit the distinct role of the dialectician in superintending the work of the name-maker while the name is being produced. ${ }^{50}$ We should see both crafts working in tandem: the dialectician identifies the object to be named and provides the name-maker with the information that needs to be embodied in a name for it. ${ }^{51}$

Ademollo further suggests that from the perspective of the dialogue the name-makers have 'got things wrong' precisely because they were not supervised by the dialecticians: this relies on his interpretation of the long etymological section that sees name-makers as erring across the board in their name-making. ${ }^{52}$ If true, however, this strengthens the case for the dialectician to supervise the name-maker if the names are to be well made. Yet it is not indeed clear that name-makers erred across the board. Sedley informs us that those words relating to cosmological themes are, in fact, judged to be correct by Socrates: only the ethical etymologies are misguided. ${ }^{53}$ One might therefore respond to Ademollo, modulo Sedley, that, perhaps, a name-maker's knowledge of the things to be named is indeed sufficient to construct some, but not all, names passably well. ${ }^{54}$

Moreover, maintaining a clear distinction between name-maker and dialectician offsets another of Ademollo's worries: namely, that one can acquire the information that a name must supply about its nominatum to perform its function from the Form of that nominatum alone, therefore one would not seem to need a separate Form of its name. ${ }^{55}$ However, the distinction between the expertises of name-maker and name-user shows us precisely why Species-Forms of names are required. The dialectician does not have the knowledge to make names; he does not know how to embody the relevant information into a name by blending sounds together to represent, by imitation or description, the complex ousiai that he wishes to separate out. There is something distinctive about the name-maker's abilities: this is his unique capacity to embody structures in sounds, thus creating a tool that can separate out an ousia. This knowledge comes from his acquaintance with the SpeciesForms of names, not the Forms of objects for which those names are intended..$^{5}$

49 Ademollo (20II) has no trouble with the reality of the distinction in these other cases.

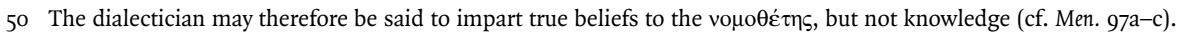

5I I thank the anonymous referee for the Cambridge Classical Journal for suggestions relating to this point. It is also important not to confuse a distinction between the distinct crafts of using and making with the requirement that there be distinct practitioners of those crafts. Thus it is possible that the original name-makers were, indeed, also dialecticians, but it does not follow that the practitioners of the two crafts are co-extensive: not all dialecticians need have the knowledge appropriate to the name-maker.

Ademollo (20II) I43, cf. 207.

Sedley (2003) e.g. 98, ro8-9.

It might be helpful here to recall the Phaedrus' (263a-266d) distinction between disputed words, and words whose meanings all agree on; dialectic is only pressed into service of disambiguating the latter.

Ademollo (20II) 138 .

Sedley (2003) 82 notes that the Species-Form of a name is clearly distinct from the Form of its nominatum 'and rightly so, since anyone trying to embody the Form of table in matter, even if that matter were vocal sound, would be making a table (albeit in this case unsuccessfully), not making a name'. 
The informational content of names can be encoded in such a way that it is only apparent to the expert. At 394a5-b7 Socrates sets up an analogy between 'the one who knows about names' (here, the dialectician) and the doctor. ${ }^{57}$ Names that are 'really the

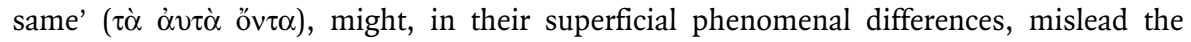
layman into thinking that they are different. However, drugs that are 'really the same' ( $\tau \dot{\alpha}$ $\dot{\alpha} v \tau \grave{\alpha}$ őv $\tau \alpha)$, but appear different to the layman because of additions or variations in

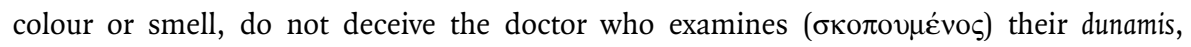
but appear the same to him. Likewise, the 'one who knows about names', the dialectician, can examine a name's dunamis and is not confused if some letter is added or changed or removed, or even if 'the dunamis of the name is in completely different letters' (394b3-6).

It has to my mind been comprehensively shown by now that in no way does this passage seem 'to make the name into a ghost that may take any form', as Robinson suggests..$^{8}$ Simply because the informational content may be embodied in different ways, this does not suggest that any concatenation of sounds will do: the name must nevertheless be susceptible of being decoded into the right informational content. We may suppose, then, that the informational content a name must provide will indeed also constrain the phonemes in which it can be embodied..$^{59}$

It is not, however, immediately obvious what Socrates means by claiming that a name has a dunamis, which, typically in Plato and elsewhere, has connotations of 'power' or 'capacity'. ${ }^{60}$ Socrates' claim, by way of illustration, that the names 'Hector' ('Holder') and 'Astyanax' ('Town-lord') (394b7-cr) share a dunamis, does not initially appear to help in deciding the matter conclusively. Sedley, considering these proper names to be 'chosen to pick out types, not individuals', suggests that both names pick out the same type (let us suppose here, a kingly nature), yet Socrates cannot consider them to be strict synonyms, since they yield partially different information concerning that type. Thus, he infers, the

57 Since the doctor is primarily an expert in using drugs, and he is presented as examining drugs, not making them, I take the 'one who knows about names' in the analogous case of naming to be the one who uses names, viz. the dialectician.

58 Robinson (1969) ir6.

59 The notion that the Species-Forms constrain the phonetic structures to the degree suggested here is also consistent with other passages in the Cratylus where Socrates appears to suggest that there is more than one phonetic structure capable of instantiating a name. At 389d4-390a, Socrates states that words of the same semantic type can have different phenomenal characteristics in different languages just as the smiths in these different countries may render the same Form 'in different iron' ( $\dot{\varepsilon} v \not \partial \lambda \lambda \omega \sigma 1 \delta \eta \dot{\rho} \rho)$ (390ar). Hence, we might infer, it is possible that, say, 'cheval', 'horse', 'equus' and i $i \pi \mathrm{s}$ are all correct names for a horse. I follow Sedley (2003, I30-I) in supposing different languages use different matter because they have different systems of basic sounds. It does not follow, then, that one can use any old matter. The key is to tighten up the definition of 'arbitrary' in play here. Socrates' radical naturalism allows for the possibility that the name of Hector could have been otherwise: it could have been 'Astyanax', for example. But to say that a name is arbitrary is not to say that a name could have had some other particular linguistic properties, but rather that it could have had any other particular linguistic properties whatsoever.

6o Barney (200I) 88n.6 provides a good overview of the uses of dunamis. I do not view the interpretation of dunamis that will be suggested here as entirely divorced from the more typical use; after all, the relevant structural properties of a name are just those properties required for it to be capable of performing a particular function. 
two names 'share the same power . . . by being extensionally equivalent'. ${ }^{\text {rI }}$ Sedley also claims that when particular names share a dunamis 'we must assume that they embody one and the same species form of name', which he has identified purely with their function. Informational content is thereby relegated to the means by which a name discharges its function, and any number of different means (although not every means), we might suppose, would serve this end equally well. ${ }^{62}$

If Socrates did consider 'Hector' and 'Astyanax' to yield different informational contents, but have the same Species-Form, my identification of informational content with what I have called the structural aspect of the Species-Form looks implausible, since then the SpeciesForm would appear to contain all possible sets of informational contents that might be used to pick out an object. ${ }^{63}$

However, it is not clear that Socrates does indeed view the two names as expressing different informational contents. In these same lines Socrates tells us that 'Astyanax' and 'Hector' signify the same thing ( $\tau \alpha$ vò̀ $\sigma \eta \mu \alpha i v \varepsilon 1$ ), despite the fact that they share none of the same letters except for tau. Since the examples of 'Hector' and 'Astyanax' are offered to clarify the claim that phenomenally different names share a dunamis, we may suppose, then, that two names share a dunamis in virtue of signifying the same thing. Thus we must consider further what Socrates means by 'signifying the same thing', and what, precisely, we are to understand as being signified. ${ }^{64}$ Sedley understands a name to signify an object by designating it in a complex way, 'by embodying in a sound the ideal function of the name of $x$, a function which is summed up as that of "separating the being" of $x$ ', and notes that 'this function may be discharged in a number of ways'. ${ }^{65}$ However,

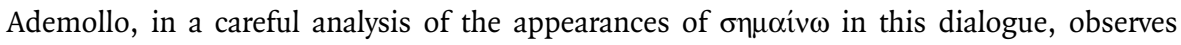
that it governs, either implicitly or explicitly, a 'that clause', from which he infers that what is signified is not, in fact, some object (or type), but the informational content (or etymological sense) that a name conveys. Thus (to use Ademollo's example), anthropos

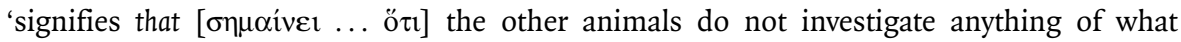
they see ... whereas the human being [no sooner has he seen it - that is ö $\pi \omega \pi \varepsilon-$ than he investigates ( $\dot{\alpha} v \alpha \theta \rho \varepsilon \hat{i})$ and reflects upon what he has seen]' (399c). ${ }^{66}$ If this is correct,

6I Sedley (2003) 84. Ademollo (20II) I75 glosses Sedley as follows: 'perhaps we might rather take the power to be something like the reference of a term as distinct from its referent.'

62 Cf. Sedley (2003) 85. Sedley carefully points out that the means cannot be dispensed with on his account.

63 Ademollo (20II) 134n.98 agrees that names instantiating the same Species-Form of name must supply the same information about their object, since otherwise, 'the form would have to be - rather unpalatably - a repository of all conceivable information about X.'

64 I focus on $\sigma \eta \mu \alpha i v \omega$ here; however, as Ademollo, I treat it as equivalent to $\delta \eta \lambda$ ó $\omega$ in the contexts of use that interest us here. Although $\delta \eta \lambda$ ó $\omega$ appears to have wider application than $\sigma \eta \mu \alpha i v \omega$ in this dialogue (cf. $433 \mathrm{~d}-\mathrm{e}$ ), the two terms are used interchangeably in the etymological discussion (e.g., the use of $\delta \eta \lambda$ ó $\omega$ in the etymology of 'ทিр fuller discussion of $\delta \eta \lambda o ́ \omega$, and the synonymy of $\delta \eta \lambda o ́ \omega$ and $\sigma \eta \mu \alpha i v \omega$ at 394c.

65 Sedley (2003) 85 .

66 For similar appearances of $\sigma \eta \mu \alpha i v \omega$ see, e.g.: 395a-b, 4I3e, 4I5c-d, 4I9e, 437a-b. For Ademollo's full analysis see

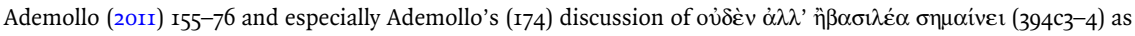


then, pace Sedley, when Socrates tells us that 'Hector' and 'Astyanax' signify the same, he does not mean that two names signify the same thing by means of different informational content, but that they signify the same informational content. ${ }^{67}$ If so, then Socrates supposes the names to be more strictly synonymous than Sedley would have us suppose. Moreover, since two names 'signifying the same' is offered as an explanation for their sharing $a$ dunamis, then sharing a dunamis does not look to be merely tantamount to extensional equivalence either. As Ademollo notes, Socrates never claims that 'Hector' and 'Astyanax' contain different informational content, only that they contain different letters. ${ }^{68}$ Furthermore, as we have seen, Socrates not only says that names that share the same dunamis, but, explicitly, that they are the same name (394a7): it would seem difficult to make sense of this on an interpretation that sees them as merely co-extensive, and in fact conveying different informational contents.

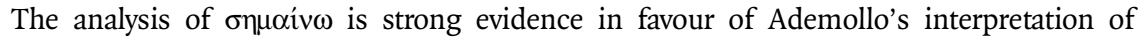
dunamis as informational content. We can also make sense of the idea that the names 'Hector' and 'Astyanax' share informational content by appeal to the earlier claim that names instantiate Species-Forms. While Sedley observes that these two names 'achieve their designating function' by providing partially different information in the process of identifying the nominatum, it is clear that the feature of the nominatum that Socrates claims they identify is the same in each case (a kingly nature); this far, at least, they appear to be providing the same information. Compare this with the case of 'Hesperus' and 'Phosphorus', whose associated descriptions (e.g. 'star that is seen in the evening', 'star that is seen in the morning') clearly pick out different features or aspects of one and the same object. ${ }^{69}$ We might learn something new by being told that Hesperus is Phosphorus. It is not clear that, given 'Hector' and 'Astyanax' both signify a kingly nature, Socrates would consider them to differ relevantly in cognitive significance: in so far as they both mean (etymologically speaking) a kingly nature, nothing new can be learned by their identification. ${ }^{70}$

This being so, more general considerations concerning the relationship between Forms and particulars might explain such minor differences between their informational contents. Socrates had earlier stated that (393a8-9) that the words 'hectōr' and 'anax' signify 'virtually

'signifying an individual object as a king - i.e. it signifies that its referent is a king', since the lack of article here suggests that it does not refer to a universal object or kind (pace Sedley). It might be tempting on my interpretation

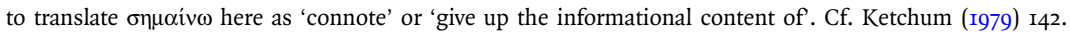

67 Cf. Socrates' earlier claim (393a8-9) that the words 'hectōr' and 'anax' signify virtually the same ( $\sigma \chi \varepsilon \delta$ óv $\tau \mathrm{\imath} \tau \alpha \tau^{\tau} \tau \mathrm{v} v$

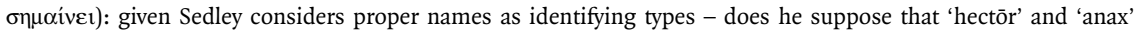
have 'almost the same' extension? Yet they would both identify exactly the same class on his reading.

68 Ademollo (20II) I73; for further criticisms of Sedley's reading see, ibid., I75.

69 Compare also with Socrates' claim at 392c-e that the women of Troy call Hector's son 'Scamandrius' while the men call him 'Astyanax'. Although the latter is said to be more correct than the former, both are acknowledged to be names for him (cf. Fine (I977) 297). It would seem that these names are co-extensive then, yet nowhere does Socrates appear to suggest that these two names have the same dunamis.

70 Of course the layman might learn something new, but that would be precisely because he is confused into thinking that they are different names because he cannot see through the sounds and syllables to their underlying informational content. 


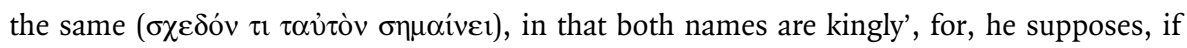
one is a lord (anax) of something, one is also a possessor (hectōr) of it. Ademollo glosses this as a sufficiency condition: being a 'town-lord' entails being a 'holder' but not vice versa. Since 'anax' (thus even more so 'Astyanax') seems to contain more specific informational content than 'Hector', it is possible, then, that the names qualifying as the same names on Socrates' account do not yield informational content concerning different features of the type in question, but informational content that more or less finely circumscribes the same features. ${ }^{7 \mathrm{I}}$ This looks to cohere nicely with the idea that the names are instantiations of a Species-Form, and, as such, approximate that Form to varying degrees. We would not expect two wool-shuttles to be identical to each other, just as they would not be identical to the Form. ${ }^{72}$ Socrates' apparently weaker claim that 'Hector' and 'Astyanax' are 'close to each other' ( $\pi \alpha \rho \alpha \pi \lambda \eta \dot{\sigma i o v})$ and 'signify roughly the same' ( $\sigma \chi \varepsilon \delta$ óv

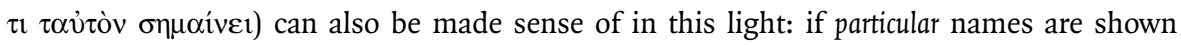
to have minor differences in informational content, which results in their describing their putative objects in a more or less fine-grained manner, this is merely a consequence of their condition as particulars. ${ }^{73}$ Nevertheless, two names would be the same in so far as they had the relevant features in common (such as containing information pertaining to a kingly nature), and thus share the same Species-Form. ${ }^{74}$

Ademollo himself concedes that Socrates' claims about the sameness of names would be 'all the more pregnant' if we could read it in the light of Socrates' discussion of Forms in the tool analogy. ${ }^{75}$ It is perhaps odd, then, that Ademollo views Species-Forms to have been replaced by a new theory by this point, reasoning that Socrates does not mention them again after the tool analogy. However, this argumentum ex silentio does not provide strong grounds: neither do we get any indication from Socrates that he has dropped them from consideration. Furthermore, we must not ignore the clue of Socrates' choice of dunamis, which in Plato's works is closely related to phusis (one of the terms we saw used to characterise Species-Forms), and also the strong parallel between Socrates' claim in the tool analogy (389d-39oa) the name-maker may set the Species-Form in different sounds and syllables, and his subsequent claim here $(393 \mathrm{~d}-\mathrm{e})$ that the name-maker may set the same dunamis in different letters. ${ }^{76}$ At any rate, the fact that Form-talk drops out of the discussion

$7 \mathrm{I}$ Ademollo (20II) 159. As for Socrates' other sets of 'near-synonyms': the more specific informational content in Iatrocles ('Doctor-Fame') likewise seems to entail that encoded in Akesimbrotos ('Mortal-Healer') (but not vice versa) (cf. 394c6); if one is a 'War-Leader' (Polemarchos) one would thereby be a 'Leader' (Agis), and the expectation would certainly be that one was 'Good-at-War' (Eupolemos).

E.g. Phd. 74d, R. 597a-b.

Cf. Cra. $432 \mathrm{aff}$.

Cf. Ademollo (20II) I7I: 'It is a genuine Platonic view that things sharing a common feature or form are the same in respect of that feature or Form. Thus at Men. 72a-c Socrates claims that bees, which are many and different from each other, "do not differ at all but are all the same" in so far as they are bees'. 
at this stage should not cause us concern. By telling Hermogenes at the start of the etymologies that the next task is to examine the correctness of names 'with those who know' (39rbg), Socrates signals a shift from an account of naming and name-making in the abstract to an account from the perspective of the craftsmen themselves: one would not expect any craftsman to describe how he practises his craft in the abstract language of the Forms.

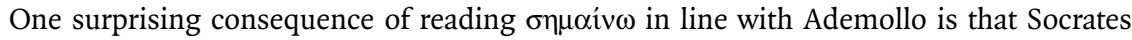
does not appear to use any term to express designation in the passage under discussion. I suspect it might help us here to recall a name's classification as a tool. Tools are used by someone for a particular task. We might reason accordingly that names do not designate their nominata per se, just as a wool-shuttle does not weave a woollen garment by itself. ${ }^{77}$ Rather it is the name user who uses a name to designate an individual. This in turn resolves a worry about how a proper name that only yields quite general information can 'designate' an individual. ${ }^{78}$ It does not. The user designates an individual: the informational content a name gives up only lends it the capacity to be so used. ${ }^{79}$ Thus, by investigating the dunamis of a name, we might suppose the user indeed discovers a capacity: what it can be used to designate, rather than what it designates per se. ${ }^{80}$

\section{Conclusion}

The tool analogy, on this interpretation, advances a radical linguistic naturalism which follows from the conjunction of certain key claims, namely: (I) objects in the world, including actions, have an objective and stable existence and are mind-independent (these claims merely exclude extreme subjectivism about naming); (2) names are a class of tools; (3) tools (at least) have both generic Forms and Species-Forms, and it is in virtue of participating in these Forms that they can successfully perform their intended functions and be the tools that they are; (4) the making of names requires a specific expertise distinct from that of using names. I have argued that the distinctive expertise of the name-maker primarily concerns the structural features a name must have in order to perform the function required of it. Since his knowledge is said to be of the SpeciesForm, correspondingly, the Species-Form must determine the structural features of a name.

77 Cf. Silverman (I992) 28.

78 Sedley (2003) may seem to fare no better here, since he suggests that the personal names Socrates offers as examples are chosen to pick out types. In virtue of what, then, does 'Hector' designate the son of Priam, rather than some other qualifying individual? Cf. Ademollo (20II) I73, and I66 on a different, but related point.

79 The etymology given of the name Pelops (as reported by MSS $\beta T \delta$ ) might speak to this: we are told it 'signifies

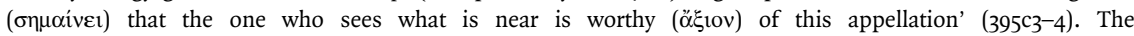
etymological analysis of this name appears to inform us who it is appropriate to use the name to designate.

8o Strawson might be sympathetic to such a view: he denies expressions have meanings per se, but considers the significance of expressions to be 'general directions for its use to refer to or mention particular objects or persons' which 'cannot be identified with the object it is used, on a particular occasion, to refer to' (I950) 327, and, "Mentioning" or "referring" is not something an expression does; it is something that someone can use an expression to do' (326). 
Understanding the Species-Form of a name as governing structural as well as functional features of particular names has the advantage of rendering the conclusions of the tool analogy non-trivial, and the tool analogy itself a substantive case against Hermogenes' claim that names are arbitrary concatenations of sounds, 'pieces of voice' whose namehood is conferred on them by agreement or fiat alone. Only a reading such as this respects the distinction between the expertise of the name-maker and of the tool-user, and the superior epistemic position of the name-maker in constructing and establishing names. It is, after all, the unique qualification of the name-maker to make names that Socrates points to when summing up his refutation of Hermogenes.

Soc: It is likely then, Hermogenes, that the setting of names is not a trivial business, as you think; nor is it the province of insignificant men or anyone who pops along. And Cratylus speaks ( $\dot{\alpha} \lambda \eta \theta \hat{\eta} \lambda \dot{\varepsilon} \gamma \varepsilon \mathfrak{c})$ when he says that names are by nature for things, and that not everyone is a craftsman of names, but only he who looks to the name which is natural for each thing and is able to set its form in letters and syllables.

39od7-e5

The claim that Species-Forms determine structural features of names also dovetails nicely with the view, expressed in etymological thesis, that names yield informational content when decoded. Since there is no indication in the text that Socrates has changed theoretical tack between the tool analogy and the etymologies it is surely to any interpretation's credit if it does not require him to.

Although the jury is out on Plato's final verdict on naming in this dialogue, a popular line of interpretation sees the mimetic theory thrown out, and agreement reinstated as the mechanism for securing reference towards the end of the dialogue at $434 \mathrm{c} \mathrm{ff}^{8 \mathrm{I}}$ A case study is made of the word $\sigma \kappa \lambda \eta \rho$ ó $\eta_{\zeta}$, which is agreed to reveal hardness to those using the word, yet is found not to contain the mimetic properties that should enable it to do so. Cratylus is left to respond that he understands what the name picks out through है $\theta$ os, which consequently must overrule the natural imitative properties that the name has. If this is so, then the etymological-mimetic theory of naming must be rejected: the mimetic properties of a name cannot explain its successfully picking out a nominatum because they are neither necessary nor sufficient for it doing so. ${ }^{82}$

8I Following others, such as Bestor (I980), Robinson (I969) and Schofield (I982), I take the dialogue to reinstate conventionalism. See, for example, Kahn (1973), Kretzmann (1971) and Sedley (2003) for opposing interpretations.

82 While this passage shows that the appropriate mimetic properties of a name are not necessary for its picking out an object, it is not as immediately obvious that they are not sufficient either; however, on this point see Smith (2008) 133-4:

Likeness cannot even be sufficient for reference. Since convention can override any already-existing putative mimetic link, there must be a further condition for successful reference: either there is a convention in place which accords with the natural relation of likeness or a supplementary understanding between two interlocutors (a convention) that no convention is in place at all. If one can use names to refer to 
What is less remarked upon, and, I hope, should be suggested to the reader on the interpretation of the tool analogy offered here, is that the rot runs deeper than this: if custom, agreement or habit can fix reference, the claim that names have Species-Forms cannot be saved either. This is because having the Species-Form of name-for-hardness suggests certain structural constraints on what a name could be like: $\sigma \kappa \lambda \eta \cot ^{\prime} \mathrm{s}$ fails to meet such requirements - perhaps it is the linguistic equivalent of trying to use a silk-shuttle to weave wool. Yet $\sigma \kappa \lambda \eta \rho$ ótn $\varsigma$ nevertheless succeeds in picking out the intended referent. Since we cannot explain how this occurs by appeal to the name's Species-Form, Species-Forms end up failing to explain the very things they were introduced to explain in the first place. ${ }^{83}$

If the claim that names have Forms entails strict naturalism in naming and that naturalism is subsequently rejected, then it follows that the claim that names have Forms must be thrown out as well. Since the claim that names have Species-Forms is central to the argument of the tool analogy, it is difficult, then, to make sense of Ademollo's claim that the tool analogy is designed to 'admit of a reinterpretation in favour of conventionalism' once we have been apprised of later developments in the dialogue. ${ }^{84}$ To reinterpret the tool analogy in this way, I submit, would involve ignoring, not reinterpreting, the claim that names are tools and, in particular, the idea that namemaking and name-using are distinct expertises. Only if Socrates has radical naturalism in mind in the tool analogy is this distinction intelligible at all.

It may be that Plato instead intentionally leaves the reader with a methodological question as to what role the Forms can play in an account of linguistic phenomena. The dialogue as a whole would therefore reveal a concern that certain phenomena may not be susceptible of an explanation that appeals to the Forms, since the resulting account cannot accommodate the certain features of actual linguistic practice. This is not tantamount to a rejection of the theory of Forms, or even, necessarily, a substantial criticism of it. Nothing follows for the explanation of other classes of particulars: it is quite possible that Plato views linguistic expressions, at least, as a special case. Perhaps, as Aristotle suggests, we are meant to conclude that it is a mistake to class names as tools. ${ }^{85}$ Or, perhaps, taking our cue from Aristotle again, we might suspect that Plato's concerns here cover a broader class of objects. Names, and tools in general, are also artefacts. Yet Aristotle testifies that Plato ended up denying that artefacts had Forms; one might then speculate that this dialogue exposes an early worry that may ultimately come to concern the possibility of artefactual Forms in general. ${ }^{86}$

nominata that they are unlike by agreeing upon the reference, then one must also secure agreement to get a name to attach to an object that it is like rather than an object it is dissimilar to.

83 Even on a view of Forms as specifying functions alone, unpalatable constraints on names would still result. For example, at $432 \mathrm{ff}$., our ability to successfully use a name, which was created for one object, to pick out another, such as successfully using the name 'Hermogenes' to pick out Cratylus ought not be possible if names had Forms that strictly specified their functions (say the function of picking out Hermogenes).

84 Ademollo (20II) 424 .

85 Aristotle Int. 4 r6b33-17a2.

86 Aristotle Metaph. A 99rb, M ro8oa, L ro7oa. Oddly enough, Ademollo (20II) II6 maintains that Aristotle is mistaken to suggest that Plato denied artefactual Forms given that his reports conflict with the passage under 


\section{Works Cited}

Ackrill, J. L. (1997) 'Language and reality in Plato's Cratylus', in (id.) (ed.) Essays on Plato and Aristotle, Oxford, 33-52.

Ademollo, F. (20II) The Cratylus of Plato: a commentary, New York.

Anagnostopoulos, G. (1972) 'Plato's Cratylus: the two theories of the correctness of names', Review of Metaphysics 25, 69I-736.

Arieti, J. A. (I99I) Interpreting Plato: the dialogues as drama, Savage, MD.

Barney, R. (I997) 'Plato on conventionalism', Phronesis 42, I43-62.

(200I) Names and nature in Plato's Cratylus, New York.

Baxter, T. M. S. (I992) The Cratylus: Plato's critique of naming, Leiden.

Bestor, T. W. (I980) 'Plato's semantics and Plato's Cratylus', Phronesis 35, 306-30.

Brock, R. (I990) 'Plato and comedy', in E. M. Craik (ed.) Owls to Athens: essays on classical subjects presented to Sir Kenneth Dover, Oxford, 39-49.

Calvert, B. (1970) 'Forms and flux in Plato's Cratylus', Phronesis I5, 26-47.

Charlton, W. (1970) Aristotle's Physics, translation with commentary, Oxford.

Davidson, D. (200I/I984) 'Communication and convention', in Inquiries into truth and interpretation, New York, 265-80.

(2001/1992) 'The second person', in Subjective, intersubjective, objective, New York, I07-22.

Evans, M. (20II) 'Plato on the norms of speech and thought', Phronesis 56, 322-49.

Gold, J. B. (1978) 'The ambiguity of "name” in Plato's Cratylus', Philosophical Studies 34, 223-5I.

Fine, G. M. (1977) 'Plato on naming', Philosophical Quarterly 27, 289-301.

Gonzalez, F. J. (1998) Dialectic and dialogue: Plato's practice of philosophical inquiry, Evanston.

Irwin, T. H. (I999) 'The theory of forms' in G. Fine (ed.) Plato, vol. I, Oxford, I43-70.

Kahn, C. H. (1973) 'Language and ontology in the Cratylus', in E. N Lee, A. P. D. Mourelatos, R. M. Rorty (eds.) Exegesis and argument: studies in Greek philosophy presented to Gregory Vlastos, Leiden, 152-76.

(I986) 'Les mots et les formes dans le Cratyle de Platon', Philosophie du langage et grammaire dans l'antiquité 6 and $7,9 \mathrm{I}-\mathrm{IO} 3$.

Keller, S. (2000) 'An interpretation of Plato's Cratylus', Phronesis 50, 284-305.

Ketchum, R. J. (I979) 'Names, forms, conventionalism: Cratylus 383-395', Phronesis 24, I33-47.

Kretzmann, N. (1971) 'Plato on the correctness of names', American Philosophical Quarterly 8, 126-38.

Laurence, S. (I996) 'A Chomskian alternative to convention-based semantics', Mind 105, 269-30I.

Levin, S. B. (200I) The ancient quarrel between philosophy and poetry revisited, Oxford.

Lewis, D. (I969) Convention, Cambridge, MA.

Millikan, R. G. (1984) Language, thought, and other biological categories: new foundations for realism, Cambridge, MA.

Nightingale, A. (2003) 'Subtext and subterfuge in Plato's Cratylus', in A. N. Michelini (ed.) Plato as author: the rhetoric of philosophy, Leiden, 223-40.

Patterson, R. (1985) Image and reality in Plato's Metaphysics, Indianapolis.

Reeve, C. D. C. (I998) Plato: Cratylus, Indianapolis/Cambridge.

Robinson, R. (I969) Essays in Greek philosophy, Oxford.

Sallis, J. (1996) Being and logos: reading the Platonic dialogues, 3rd edn, Bloomington, IN.

Schofield, M (1972) 'A displacement in the text of the Cratylus', Classical Quarterly 22, 246-53.

(I982) 'The dénouement of the Cratylus' in M. Schofield and M. Nussbaum (eds) Language and logos Cambridge, 6I-8I.

consideration here, yet expresses suspicions (125) that we need to dispose of the idea of the Forms of names, given the conclusions of the dialogue. Yet if the Forms in question are ultimately to be thrown out, then our passages may not represent Plato's own considered views on the matter. 
Sedley, D. (1998) 'The etymologies in Plato's Cratylus', Journal of Hellenic Studies II8, I40-54. (2003) Plato's Cratylus, Cambridge.

Silverman, A. (1992) 'Plato's Cratylus: the naming of nature and the nature of naming', Oxford studies in Ancient Philosophy Io, 25-72.

Smith, I. (2008) 'False names, demonstratives, and the refutation of linguistic naturalism in Plato's Cratylus, 427dI-43Ic3.' Phronesis 53, I25-5I.

Strawson, P. F. (1950) 'On referring', Mind 59, 320-44.

White, F.C. (I978) 'On essences in the Cratylus', Southern Journal of Philosophy I6, 259-74.

Williams, B. (I982) 'Cratylus' theory of names and its refutation', in M. Schofield, M. Nussbaum (eds.) Language and logos, Cambridge, 83-93. 